\title{
Role of tapentadol in pain management
}

\author{
*Dr Victor Mendis \\ Consultant in Pain Medicine and Anaesthesia, Mid Essex \\ Hospitals NHS Trust, Broomfield Hospital, Chelmsford, Essex, UK
}

*Corresponding author: victor.mendis@meht.nhs.uk

\section{This article is reprinted by kind permission from the British Journal of Hospital Medicine} 73(3):143-147(March 2012). www.bjhm.co.uk.

This article reviews tapentadol, a novel centrally-acting opioid analgesic that exerts its analgesic effects through muopioid receptor agonism and additionally via noradrenaline reuptake inhibition and so potentially has a role in the treatment of both nociceptive and neuropathic pain.

Appropriate management of acute, chronic and cancer pain remains a considerable challenge for health-care providers. The physiological and psychological effects of uncontrolled pain lead to unnecessary suffering and financial loss, not only to the individual concerned but to the family and society. Current pharmacological treatment options for the management of pain are limited by significant side effects affecting the CNS, cardiovascular system, gastrointestinal system and the respiratory system.

Keywords: tapentadol; centrally acting opioid; acute and chronic pain

\section{Mechanism of action}

Tapentadol is a novel centrally-acting synthetic analgesic licensed in the UK for the management of severe chronic pain (Palexia SR; tapentadol prolonged release) and moderate to severe acute pain (Palexia; tapentadol immediate release) in adults, which can be adequately managed only with opioid analgesics ${ }^{1,2}$. Its analgesic efficacy is thought to be the result of mu-opioid receptor agonist activity and noradrenaline reuptake inhibition, with both mechanisms residing in a single molecule. Combining mu-opioid receptor agonism with monoamine reuptake inhibition is useful to improve the therapeutic range of opioids. The different, complementary mechanisms of action may additively or even synergistically increase the analgesic efficacy and/or attenuate the side effects of mu-opioid receptor agonists by reducing the requirement for mu-opioid receptor activation. The facilitation of monoaminergic transmission in descending pain inhibitory pathways in the spinal cord seems to be an important mechanism because compounds that block the reuptake of noradrenaline and/or serotonin (5-hydroxytryptamine; 5-HT) are efficacious in the treatment of chronic pain conditions $^{3,4}$ and can enhance the analgesic effect of morphine ${ }^{5}$. This is fairly important because neuropathic pain is generally considered to be relatively unresponsive to opioids ${ }^{6}$ and/or difficult to treat effectively because of mu-opioid receptorrelated side effects ${ }^{7}$.

The pharmacological profile of tapentadol confers potential advantages over other agents such as tramadol that also combine mu-opioid receptor agonism and noradrenaline reuptake inhibition. Tramadol is an atypical, racemic opioid that combines weak mu-opioid receptor activation with noradrenaline reuptake inhibition and inhibition of $5-\mathrm{HT}^{8}$. Tramadol is metabolized to an active Odesmethylmetabolite ${ }^{9}$. As the parent molecule is metabolized, the contribution of 5-HT and noradrenaline reuptake inhibition is reduced, whereas the contribution of mu-opioid receptor agonism increases, resulting in a complex timeand metabolism-dependent pattern of pharmacological activities. Because tramadol is mainly metabolized via cytochrome P450 2D6 (CYP2D6), which is polymorphic in humans, approximately $5-15 \%$ of the white population are 'poor metabolizers' of tramadol and do not experience satisfactory analgesia with standard doses $^{10}$. The analgesic effects of tapentadol on the other hand are independent of metabolic activation, and it has no active metabolites ${ }^{11}$. 
As the analgesic actions reside in a single enantiomer without requiring metabolic activation, the relative contributions of mu-opioid receptor agonism and noradrenaline reuptake inhibition remain constant. These complementary mechanisms of action may explain the broad clinical efficacy reported in nociceptive and neuropathic pain ${ }^{12-18}$.

Table 1 Comparison of tapentadol and tramadol

\begin{tabular}{|c|c|c|}
\hline & Tapentadol & Tramadol \\
\hline Molecule & $\begin{array}{l}\text { Single } \\
\text { enantiomer }\end{array}$ & Racemic mixture \\
\hline Mechanism & $\begin{array}{l}\text { Mu opioid } \\
\text { receptor agonist } \\
\text { and } \\
\text { noradrenaline } \\
\text { reuptake inhibitor }\end{array}$ & $\begin{array}{l}\text { Mu opioid receptor } \\
\text { agonist, noradrenaline } \\
\text { reuptake inhibitor and 5- } \\
\text { hydroxytryptamine } \\
\text { inhibitor }\end{array}$ \\
\hline Metabolism & $\begin{array}{l}\text { Does not require } \\
\text { metabolic } \\
\text { activation. } \\
\text { Metabolized by } \\
\text { conjugation with } \\
\text { glucuronidic acid }\end{array}$ & $\begin{array}{l}\text { Requires metabolic } \\
\text { activation via } \\
\text { cytochrome P450 which } \\
\text { is polymorphic in } \\
\text { humans }\end{array}$ \\
\hline $\begin{array}{l}\text { Side } \\
\text { effects }\end{array}$ & $\begin{array}{l}\text { No serotonin } \\
\text { syndrome }\end{array}$ & Serotonin syndrome \\
\hline $\begin{array}{l}\text { Active } \\
\text { metabolites }\end{array}$ & None & $\begin{array}{l}\text { Accumulation can lead } \\
\text { to side effects and may } \\
\text { need dose adjustments }\end{array}$ \\
\hline $\begin{array}{l}\text { Drug } \\
\text { interactions }\end{array}$ & Less common & $\begin{array}{l}\text { More common as a } \\
\text { result of dependence of } \\
\text { liver enzymes that also } \\
\text { metabolize other drugs }\end{array}$ \\
\hline
\end{tabular}

\section{Pharmacodynamics}

Tapentadol is 18 times less potent than morphine in binding to the human mu-opioid receptor and is 2-3 times less potent in producing analgesia in animal models. In-vitro radio ligand binding assays in rat brain membrane preparations have shown tapentadol to have only a modest affinity for the mu-opioid receptor relative to pure muopioid receptor agonists such as oxycodone ormorphine $^{19}$, while in-vivo intra cerebral microdialysis studies in rats have shown that tapentadol, in contrast to morphine, produces large increases in extracellular levels of noradrenaline 20 . It has been suggested that the potential for lower reliance on mu-opioid receptor agonism to produce its analgesic effects, because of the contribution of the noradrenaline reuptake inhibition component, may account for the significantly lower level of opioid-associated side effects compared to equi-analgesic doses of oxycodone in clinical trials of tapentadol prolonged release ${ }^{17}$. Furthermore, because of the lack of significant clinical serotonergic activity with tapentadol, pain facilitation via the descending transmission system is not enhanced, and the side effects caused by increased serotonin in the CNS and the enteric nervous system are avoided $^{21}$.

\section{Pharmacokinetics}

\section{Absorption}

The mean absolute bioavailability after singledose administration is approximately $32 \%$ because of the extensive first pass metabolism of tapentadol. Maximum serum concentrations of tapentadol are typically observed at around 1.25 hours after dosing with tapentadol immediate release $^{1}$ and at around 3-6 hours after dosing with tapentadol prolonged release ${ }^{2}$.

\section{Metabolism and excretion}

In humans, the metabolism of tapentadol is extensive with about $97 \%$ of the parent compound being metabolized. As discussed previously, the major pathway for metabolism is glucuronidation with $55 \%$ of orally administered tapentadol being metabolized to tapentadol - O-glucoronide. Only a small amount is metabolized by phase 1 oxidative pathways; $13 \%$ of orally administered tapentadol is metabolized by CYP2C9 and CYP2C19 to inactive $\mathrm{N}$-desmethyl tapentadol and $2 \%$ is converted to inactive hydroxyl tapentadol by CYP2D $6^{20}$.

Tapentadol and its metabolites are excreted almost exclusively (99\%) via the kidneys. The terminal half-life is on average 4 hours after oral administration and the total clearance is $1530+/-$ $177 \mathrm{ml} / \mathrm{min}^{1,2}$.

\section{Structure}

The structure of tapentadol hydrochloride is shown in Figure 1. 
Figure 1 Structure of tapentadol hydrochloride. Adapted from Tzschentke et al (2007).

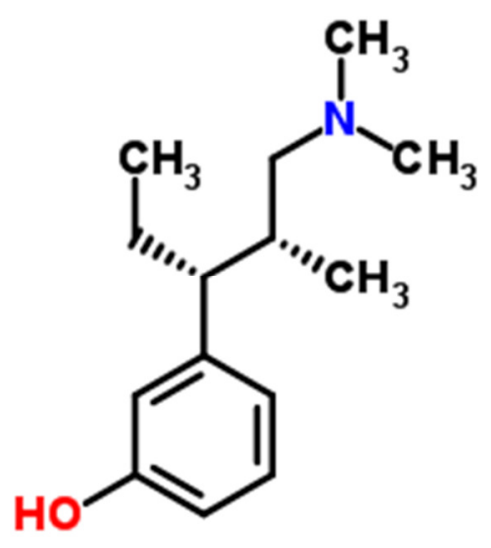

\section{Current indications for use of tapentadol}

Tapentadol is licensed in the UK for the management of severe chronic pain (tapentadol prolonged release) and moderate to severe acute pain (tapentadol immediate release) in adults, which can be adequately managed only with opioid analgesics ${ }^{1,2}$. These conditions are:

1. Moderate to severe acute pain (post-surgical)

2. Moderate to severe chronic low back pain

3. Severe chronic pain caused by osteoarthritis of the knee

4. Painful diabetic neuropathy.

\section{Clinical studies}

Tapentadol immediate release for moderate to severe acute pain

The efficacy of tapentadol immediate release for the relief of moderate to severe acute pain has been evaluated in phase III studies in patients with postoperative (bunionectomy) pain ${ }^{12,13}$ and patients with pain related to end stage degenerative joint disease awaiting primary joint replacement surgery ${ }^{14}$. Efficacy of tapentadol immediate release has also been assessed as a secondary end point in a phase III 90-day safety study in patients with lower back pain or osteoarthritis of the hip or knee ${ }^{22}$.

In a randomized, double-blind, placebo- and active controlled, parallel group, multi-centre phase III study in 603 patients with postoperative (bunionectomy) pain, treatment with tapentadol immediate release $50 \mathrm{mg}, 75 \mathrm{mg}$ and $100 \mathrm{mg}$ over a 72-hour period provided statistically significantly superior analgesia compared with placebo ${ }^{12}$. The most common adverse events, occurring in $\geq 5 \%$ of patients in any group were nausea, vomiting, constipation, dizziness and somnolence. Post-hoc analyses revealed that tapentadol immediate release $100 \mathrm{mg}$ provided comparable analgesia to oxycodone $\mathrm{HCl}$ immediate release $15 \mathrm{mg}$ with a significantly lower incidence of nausea and/or vomiting. In a similarly designed study in 901 patients with postoperative (bunionectomy) pain assessing tapentadol immediate release $50 \mathrm{mg}$ and $75 \mathrm{mg} v \mathrm{~s}$ placebo and oxycodone $\mathrm{HCl}$ immediate release $10 \mathrm{mg}$, analgesic efficacy of both doses of tapentadol was statistically superior to placebo and non-inferior to oxycodone $\mathrm{HCl}$ immediate release $10 \mathrm{mg}^{13}$. In this study, tapentadol immediate release $50 \mathrm{mg}$ resulted in a numerically lower incidence of nausea, and tapentadol immediate release $75 \mathrm{mg}$ in a statistically lower incidence of nausea and/or vomiting compared with oxycodone $\mathrm{HCl}$ immediate release $10 \mathrm{mg}$.

Hartrick et al ${ }^{14}$ also reported non-inferior analgesic efficacy and superior gastrointestinal tolerability of tapentadol immediate release $(50$ or $75 \mathrm{mg})$ compared with oxycodone immediate release $(10$ $\mathrm{mg}$ ) in a 10-day phase III, randomized, doubleblind, active- and placebo-controlled study in 666 patients with pain related to degenerative joint disease awaiting primary joint replacement.

In the phase III, randomized, double-blind, active controlled, parallel group, multi-centre, 90-day safety study in 849 patients with lower back pain or osteoarthritis of the hip or knee, tapentadol immediate release was associated with substantially better gastrointestinal tolerability while achieving similar analgesic efficacy compared with oxycodone $\mathrm{HCl}$ immediate release $^{22}$; the mean total daily dose was $284 \mathrm{mg}$ in the tapentadol immediate release group and $42 \mathrm{mg}$ in the oxycodone immediate release group. The percentage of patients discontinuing as a result of adverse events was lower in the tapentadol immediate release group (20.8\%) compared to the oxycodone immediate release group (30.6\%) with a significant difference in the distribution of times to discontinuation as a result of adverse events, patients in the oxycodone immediate release group consistently discontinuing earlier than patients in the tapentadol immediate release group. 
Tapentadol prolonged release for the management of chronic low back pain

In a prospective, randomized, double blind, activeand placebo-controlled, multicentre, phase III study in 981 patients with moderate to severe chronic low back pain, tapentadol prolonged release (100-250mg twice daily) and oxycodone controlled release $(20-50 \mathrm{mg}$ twice daily) significantly reduced mean pain intensity compared with placebo over the treatment period (3-week titration followed by 12-week maintenance period $)^{16}$. This study did not directly compare the analgesic efficacy of tapentadol prolonged release and oxycodone controlled release, but the data suggest similar efficacy and a dose equivalency of approximately $5: 1$ for tapentadol prolonged release to oxycodone controlled release. The most common treatment emergent adverse events (reported by $\geq 10 \%$ patients in any group) were nausea, constipation, headache, vomiting, dizziness, pruritus and somnolence. The incidence of vomiting, constipation and pruritus in the tapentadol prolonged release group was reported to be approximately half of that in the oxycodone controlled release group, and the odds of experiencing constipation or the composite of nausea and/or vomiting were significantly lower for tapentadol prolonged release compared to oxycodone controlled release.

A randomized, open-label phase III study assessed the long-term safety and tolerability of tapentadol prolonged release in 1121 patients with chronic knee or hip osteoarthritis pain, or lower back pain $^{23}$.Patients received controlled, adjustable, oral, twice daily doses of tapentadol prolonged release (100-250mg twice daily) or oxycodone $\mathrm{HCl}$ controlled release (20-50mg twice daily) for up to 1 year.

The median duration of treatment for the safety population was more than four times longer in the tapentadol prolonged release group (268.0 days; range 1-385 days) than in the oxycodone controlled release group (59.0 days; range 1-384 days) and the most common reason for treatment discontinuation in both groups was adverse events (22.7\% for tapentadol prolonged release and $36.8 \%$ for oxycodone controlled release). The most common treatment emergent adverse events ( $\geq 10 \%$ of patients in either treatment group) were constipation, nausea, dizziness, somnolence, vomiting, headache, fatigue and pruritus. The incidence of gastrointestinal treatment emergent adverse events, including nausea, vomiting or constipation, that led to study discontinuation was lower in the tapentadol prolonged release group $(8.6 \%)$ than in the oxycodone controlled release group $(21.5 \%)$. For patients completing the study, the mean total daily dose of both tapentadol prolonged release and oxycodone controlled release increased sharply during the first 4 weeks of the treatment period (dose titration), then remained approximately stable at tapentadol prolonged release $390 \mathrm{mg}$ and oxycodone $\mathrm{HCl}$ controlled release $74 \mathrm{mg}$ for the remainder of the study giving the same approximate dose equivalency of 5:1 as reported by Buynak et $\mathrm{al}^{16}$.

Tapentadol prolonged release and oxycodone controlled release showed similar analgesic efficacy; baseline mean (standard error) pain intensity scores in the tapentadol prolonged release and oxycodone controlled release groups respectively were $7.6(0.05)$ and $7.6(0.11)$; at end point the mean (standard error) pain intensity scores were decreased to $4.4(0.09)$ and $4.5(0.17)$ with the scores remaining stable for the maintenance period. The authors suggest that the stability of the mean total daily dose and of the analgesic effect over the maintenance period (week 4 to week 52) support that there was no acquired tolerance at the dose range tested over the 1-year period.

\section{Tapentadol prolonged release in severe chronic pain related to osteoarthritis}

In a randomized, double-blind, placebo and activecontrolled, parallel-arm, multi-centre study, a total of 1030 patients with chronic osteoarthritis-related knee pain, patients received twice-daily doses of tapentadol prolonged release 100-250mg, oxycodone controlled release $20-50 \mathrm{mg}$ or placebo for a total of 15 weeks (3-week titration and 12week maintenance period) ${ }^{15}$. Both tapentadol prolonged release and oxycodone controlled release significantly reduced mean pain intensity scores throughout the treatment period (3-week titration,12-week maintenance period) with reported mean total daily doses of approximately 
350mg for tapentadol prolonged release and 70mg for oxycodone controlled release remaining stable during the maintenance period, again yielding a dose equivalency of $5: 1$. The most common treatment emergent adverse events $(\geq 10 \%$ patients) in the active treatment groups were nausea, vomiting, constipation, dizziness, headache, somnolence, fatigue and pruritus. Incidences of constipation and the composite of nausea and/or vomiting were significantly lower in the tapentadol prolonged release group (constipation $18.9 \%$, nausea and/or vomiting $22.7 \%$ ) compared to the oxycodone controlled release group (constipation $36.8 \%$, nausea and/or vomiting $40.6 \%$ ).

The improved overall and gastrointestinal tolerability of tapentadol prolonged release are clinically important findings, as tapentadol prolonged release provided more consistent pain relief with better tolerability than oxycodone controlled release, thus allowing patients to adhere to treatment for longer periods of time.

\section{Tapentadol prolonged release in painful diabetic peripheral neuropathy}

Painful diabetic peripheral neuropathy affects 10 $20 \%$ of patients with diabetes and is often difficult to treat. Because of its complex pathophysiology involving both central and peripheral mechanisms, these patients usually require treatment with multiple agents.

In a randomized withdrawal (enriched enrolment), placebo-controlled, double-blind, parallel-group trial in a total of 591 patients with moderate to severe pain from diabetic peripheral neuropathy, tapentadol prolonged release 100-250mg twice daily provided a statistically significant difference in maintenance of a clinically important improvement in pain compared with placebo and was well tolerated ${ }^{18}$. The most common treatment emergent adverse events that occurred during the double blind period with tapentadol prolonged release included nausea (13.8\%), anxiety $(9.2 \%)$, diarrhoea (8.2\%) and dizziness (7.7\%).

The demonstrated safety and efficacy of tapentadol prolonged release in multiple chronic pain populations suggest that it may be particularly useful in pain states with both nociceptive and neuropathic components.

\section{Guidance}

The National Institute for Health and Clinical Excellence has not carried out an appraisal of either Palexia or Palexia SR. The Scottish Medicines Consortium (2011) recommended Palexia SR for use in NHS Scotland for the treatment of patients with severe chronic pain, for whom morphine sulphate modified release has failed to provide adequate pain control or is not tolerated.

\section{Dosage and administration}

As with many centrally acting analgesic medications, the dosing regimen should be individualized according to the severity of pain being treated. Tapentadol prolonged release 100$250 \mathrm{mg}$ twice daily has demonstrated efficacy and tolerability in the management of moderate to severe chronic osteoarthritis of the $\mathrm{knee}^{15}$, moderate to severe chronic low back pain ${ }^{16}$, and painful diabetic peripheral neuropathy ${ }^{18}$.Tapentadol 50-75mg (4-6-hourly) has demonstrated efficacy and tolerability in the management of moderate to severe postoperative (bunionectomy) pain ${ }^{12,13}$, of moderate to severe pain related to degenerative joint disease ${ }^{14}$ and moderate to severe lower back pain and pain from osteoarthritis of the hip or knee ${ }^{20}$.

\section{Contraindications \\ Impaired pulmonary function}

Like any other drug with mu-opioid agonist activity, tapentadol immediate or prolonged release is contraindicated in patients with significant respiratory depression in unmonitored settings or the absence of resuscitative equipment.

\section{Monoamine oxidase inhibitors}

Tapentadol immediate or prolonged release is contraindicated in patients who are receiving monoamine oxidase inhibitors or who have taken them within the last 14 days because of potential additive effects on nor-adrenaline levels which may result in adverse cardiovascular events.

\section{Paralytic ileus}

Like any drugs with mu-opioid agonist activity tapentadol immediate or prolonged release is 
contraindicated in any patient who has or is suspected of having paralytic ileus.

\section{Adverse events}

The adverse drug reactions that were experienced by patients in the aforementioned trials were predominantly of mild to moderate severity. The very common adverse events reported were gastrointestinal and CNS events such as nausea, dizziness, constipation, headache and somnolence. However, tapentadol prolonged release demonstrates significant reductions in gastro intestinal side effects when compared with equianalgesic doses of oxycodone controlled release, associated with patients remaining on therapy for longer ${ }^{17}$.

\section{Cautions}

Tapentadol immediate or prolonged release should be administered with caution to patients with respiratory depression. Patients receiving other mu-opioid receptor agonist analgesics, phenothiazines, sedative agents or other CNS depressants concomitantly with tapentadol may exhibit additive CNS depression. Tapentadol immediate or prolonged release should not be used in patients who may be susceptible to the effects of raised CSF pressure, including patients with evidence of head injury and increased intracranial pressure.

Tapentadol immediate or prolonged release is a mu opioid agonist and is a schedule II controlled substance. It can be abused in a manner similar to other opioid agonists.

\section{Conclusions}

Tapentadol (immediate or prolonged release) is a novel orally-available centrally-acting opioid analgesic combining mu-opioid receptor agonism and noradrenaline reuptake inhibition in a single molecule. It has been shown to be effective in managing moderate to severe acute nociceptive pain, and severe chronic nociceptive and neuropathic pain. At equi-analgesic doses, tapentadol appears to have an improved gastrointestinal tolerability profile as well as lower rates of discontinuation as a result of side effects compared to oxycodone.

Conflict of interest: DrV Mendis was a principal investigator for the open label phase III drug trial on tapentadol conducted by Grunenthal Ltd and has received funding for sitting on advisory boards, chairing the drug launch in Essex and giving talks for GPs.

\section{KEY POINTS}

- Tapentadol is a novel centrally-acting analgesic with a dual mode of action MORNRI.

- It appears to have fewer gastrointestinal side effects compared to other opioids of similar efficacy, and thus patients remain on therapy for longer.

- Its analgesic effects are independent of metabolic activation.

- Tapentadol has no active metabolites.

- It is an effective analgesic for a wide range of acute and chronic pain conditions.

- Owing to its dual mechanism of action, tapentadol is effective for the treatment of both nociceptive and neuropathic pain conditions.

\section{References}

1. Grunenthal Ltd (2011a) Summary of Product Characteristics Palexia $50 \mathrm{mg}$ film-coated tablets.

www.medicines.org.uk/EMC/medicine/24387/ SPC/Palexia+50+mg+filmcoated+tablets/(accessed21February2012)

2. . Grunenthal Ltd (2011b) Summary of Product Characteristics Palexia SR $50 \mathrm{mg}$ prolongedrelease tablets. www.medicines.org.uk/EMC/medicine/24389/ $\mathrm{SPC} / \mathrm{Palexia}+\mathrm{SR}+50+\mathrm{mg}+$ prolongedrelease + ta blets/ (accessed 21 February 2012)

3. Carter GT, Sullivan MD. Antidepressants in pain management. CurrOpinInvestig Drugs 2002;3:454-8

PMid:12054096

4. Tzschentke TM NA and 5-HT reuptake inhibitors and 2 agonists. In: Buschmann $\mathrm{H}$, Christoph T, Friderichs E, Maul C,Sundermann B, eds. Analgesics. From Chemistry and Pharmacology to Clinical Application. Wiley-VHC, Weinheim, Germany: 2002:264-82

5. Ossipov MH, Malseed RT, Goldstein FJ. Augmentation of central and peripheral morphine analgesia by desipramine. Arch IntPharmacodyn 1982: 259: 222-9 PMid:7181579 
6. Mao J, Price DD, Lu J, Keniston L, Mayer DJ. Two distinctive anti nociceptive systems in rats with pathological pain. NeurosciLett 2000: 280:13-16

http://dx.doi.org/10.1016/S0304-

3940(99)00998-2

7. Martin TJ, Eisenach JC. Pharmacology of opioid and nonopioid analgesics in chronic pain states. J PharmacolExpTher 2001:299: 811-17 PMid:11714863

8. Raffa RB, Friderichs E, Reimann W, Shank RP, Codd EE, Vaught JL. Opioid and nonopioid components independently contribute to the mechanism of action of tramadol, an 'atypical' opioid analgesic. J PharmacolExpTher 1992:260: 275-85 PMid:1309873

9. Lintz W, Erlacin S, Frankus E, Uragg $\mathrm{H}$. Biotransformation of tramadol in man and animal [German]. Arzneimittelforschung 1981:31:1932-43

PMid:7198474

10. Poulsen L, Arendt-Nielsen L, Brosen K, Sindrup SH. The hypoalgesic effect of tramadol in relation to CYP2D6. ClinPharmacolTher 1996:60: 636-44 http://dx.doi.org/10.1016/S00099236(96)90211-8

11. Terlinden R, Kogel B, Englberger W, Tzschentke $T$. In vitro and in vivo characterization of tapentadol metabolites. Methods Find ExpClinPharmacol 2010:32(1): 31-8 http://dx.doi.org/10.1358/mf.2010.32.1.14341 65 PMid:20383344

12. Daniels SE, Upmalis D, Okamoto A, Lange C, Haeussler J. A randomized, double-blind, phase III study comparing multiple doses of tapentadol IR, oxycodone IR, and placebo for postoperative (bunionectomy) pain. Curr Med Res Opin 2009a:25(3):765-76 http://dx.doi.org/10.1185/03007990902728183 PMid:19203298

13. Daniels S, Casson E, Stegmann JU et al. A randomized, double-blind, placebo-controlled phase 3 study of the relative efficacy and tolerability of tapentadol IR and oxycodone IR for acute pain. Curr Med Res Opin 2009b:23(6):1551-61

http://dx.doi.org/10.1185/03007990902952825 PMid:19445652

14. Hartrick C, Van Hove I, Stegmann JU, Oh C, Upmalis D. Efficacy and tolerability of tapentadol immediate release and oxycodone
HCI immediate release in patients awaiting primary joint replacement surgery for endstage joint disease: a 10 day, phase III, randomised, double-blind, active- and placebocontrolled study. ClinTher 2009:31(2): 260-71 http://dx.doi.org/10.1016/j.clinthera.2009.02.0 09

PMid:19302899

15. Afilalo M, Etropolski MS, Kuperwasser B et al. Efficacy and safety of Tapentadol extended release compared with oxycodone controlled release for the management of moderate to severe chronic pain related to osteoarthritis of the knee: a randomized,double-blind, placeboand active-controlled phase III study. Clin Drug Investig 2010; 30(8): 489-505 http://dx.doi.org/10.2165/11533440000000000-00000

PMid:20586515

16. Buynak R, Shapiro DY, Okamoto A et al. Efficacy and safety of tapentadol extended release for the management of chronic low back pain: results of a prospective, randomized, double-blind,placebo- and activecontrolled phase III study. Expert OpinPharmacother 2010:11(11): 1787-804 http://dx.doi.org/10.1517/14656566.2010.4977 20 PMid:20578811

17. Lange B, Kuperwasser B, Okamoto A et al. Efficacy and safety of tapentadol prolonged release for chronic osteoarthritis pain and low back pain. AdvTher 2010:27: 381-99 http://dx.doi.org/10.1007/s12325-010-0036-3 PMid:20556560

18. Schwartz S, Etropolski M, Shapiro DY et al. Safety and efficacy of tapentadol ER in patients with painful diabetic neuropathy: results of a randomized-withdrawal, placebocontrolled trial. Curr Med Res Opin 2011:27(1):151-62 http://dx.doi.org/10.1185/03007995.2010.5375 89

PMid:21162697

19. Monory K, Greiner E, Sartania N et al. Opioid binding profiles of new hydrazone, oxime, carbazone and semicarbazone derivatives of 14-alkoxymorphinans. Life Sci 1999:64(22): 2011-20 http://dx.doi.org/10.1016/S00243205(99)00148-4

20. Tzschentke TM, Christoph T, Kogel B et al. ()-(1R,2R)-3-(3-Dimethylamino-1-ethyl-2methyl-propyl)-phenol Hydrochloride (TapentadolHCl): a novel opioid receptor agonist/norepinephrine reuptake inhibitor with 
broad-spectrum analgesic properties. $\mathrm{J}$ PharmacolExpTher 2007:323: 265-76 http://dx.doi.org/10.1124/jpet.107.126052

PMid:17656655

21. Kress HG. Tapentadol and its two mechanisms of action: Is there a new pharmacological class of centrally-acting analgesics on the horizon? Eur J Pain 2010:14: 781-3 http://dx.doi.org/10.1016/j.ejpain.2010.06.017 PMid:20659810

22. Hale M, Upmalis D, Okamoto A, Lange C, Rauschkolb C. Tolerability of tapentadol immediate release in patients with lower back pain or osteoarthritis of the hip or knee over 90 days: a randomized, double-blind study. Curr Med Res Opin 2009:25(5): 1095- 104 http://dx.doi.org/10.1185/03007990902816970 PMid:19301989

23. Wild JE, Grond S, Kuperwasser B et al. Long term safety and tolerability of tapentadol extended release for the management of chronic low back pain or osteoarthritis pain. Pain Pract 2010:10(5): 416-27 http://dx.doi.org/10.1111/j.15332500.2010.00397.x

PMid:20602712

24. Scottish Medicines Consortium (2011) Resubmission. Tapentadol, 50,100, 150, 200 and $250 \mathrm{mg}$ prolonged-release tablets (PalexiaR SR). SMC No. (654/10). www.scottishmedicines.org.uk/files/advice/tap entadol_Palexia_SR_RESUBMISISON_FINA L_MAY_2011_for_website.pdf (accessed 21 February 2012)

25. Tzchentke TM, De Vry J, Terlinden R et al (2006) Tapentadol hydrochloride. Drugs of future.31:1053-61

http://dx.doi.org/10.1358/dof.2006.031.12.104

7744 